\title{
Jetzt rede ich
}

\author{
B. Gurtner
}

Also, eigentlich könnte ich meine Story an den Blick verkaufen. Für teures Geld. Das würde meine schäbige Rente etwas aufbessern. Seit zwei Monaten bin ich pensioniert. Und jetzt rede ich. Schonungslos, über alles. Ich schicke es der Ärztezeitung, dem gelben Heftli. Wir in der Pflege sind ja eine Art Kollegen, obwohl die medizinischen Herren nicht gerne auf uns hören. Auch viele junge Ärztinnen meinen, sie wüssten alles besser als die Pflegerinnen. Die hätten doch viel mehr Erfahrungen. Schmutzige Wäsche soll aber unter uns bleiben. Sonst machen die Journalisten gleich wieder ein Geschrei.

Wissen Sie, unser altes Krankenheim ist eigentlich ein krankes Altersheim geworden. Die sparen es noch zu Tode. Bis jetzt haben wir immer wieder einen Zacken zugelegt. Kurz vor meinem Weggang haben sie aber nochmals drei Stellen gestrichen. Jetzt muss in der Nacht eine Diplomierte mit einer einzigen Hilfe zwei Stockwerke besorgen. Und alle Leistungsblätter selber ausfüllen. Geht doch nicht. Das gibt nur immer mehr Dekubitüsser. Mit allen Folgen. Und immer mehr Überstunden, weil vor dem Schlafen viele Bettlägerige nochmals trockengelegt werden müssen. Du kannst doch nicht alles der Nachtschicht überlassen. Spät wird es auch, wenn Dr. A. seine Patientinnen oft erst nach dem Abendessen besucht und auf seinen unangemeldeten Blitzvisiten tausend Wünsche und Reklamationen anbringt, obwohl die Zuständigen schon weg sind. Die Oberschwester - neuerdings heisst sie Pflegebereichsleiterin - sie hat ihm mehrmals erklärt, dass es so nicht geht. Lange genützt hat es nie. Der Direktor schweigt, weil Dr. A. im Stiftungsrat ist und in der gleichen Partei. Und so machen auch die meisten anderen Ärzte ihre Visiten, wenn es ihnen gerade passt und erwarten, dass wir jederzeit subito zur Verfügung stehen.

Mag mir jemand erklären, warum sieben Belegärzte und fünf Ärztinnen 30 verschiedene Blutdruckpillen und 20 Schlafmittel brauchen? Die konnten sich noch nie auf eine gemeinsame Medikamentenliste einigen. Nach jeder Fernsehsendung von Dr. Stutz verordnen sie den neuesten Hit, koste es, was es wolle. Dr. B. kam von der Uniklinik zu uns aufs Land und hat sofort verlangt, dass intravenöse statt subkutane Infusionen angelegt werden. Auch dann, wenn es ausser Grübeleien, Hämatomen und viel Aufregung gar nichts brachte. Erst als ihm Dr. C. einen Bericht aus Amerika zeigte, wo sie in einer berühmten Klinik Flüssigkeit ebenfalls subkutan ersetzen, durften wir es wieder wie vorher machen. Im letzten Herbst flog der gleiche Dr. B. an einen Kongress. Darauf wollte er bei uns perkutane Magensonden einführen. Also natürlich nicht bei uns Pflegern, aber bei Heimbewohnern, die er nie sterben lassen will.

Frau Dr. E. merkt rasch, wenn hinter Unruhe oder Appetitmangel ein psychisches Problem steckt. Aber sie verordnet immer so hoch dosiert, dass die Patienten ganz steif werden und stürzen, weil sie stolpern oder weil ihr Blutdruck im Stehen abfällt. Doch wer misst schon im Stehen? Frau Dr. F. ist da viel vorsichtiger. Sie stoppt für drei Tage alle Medikamente, wenn es den Kranken unerklärlich schlechter geht. Das wirkt oft Wunder. Auch sonst setzt sie immer ein bisheriges Mittel ab, bevor sie ein neues verordnet. Bei ihr muss niemand jeden Tag 26 Tabletten und Kapseln einnehmen. Ehrenwort, die reine Nebenwirklichkeit: 26 Schluckstücke waren der Rekord bei einer Patientin von Dr. G., den wir nur «Pillenfritz» nennen.

Dr. H. redet so leise und schnell, dass niemand sein Fachchinesisch versteht. Die Kranken nicht, die Pflege nicht, und auch die Angehörigen nicht. Aber mit denen spricht er sowieso kaum je ein Wort. Wenn er es doch einmal tat, erfuhren wir nie, was er ihnen gesagt hatte. Dr. K. spricht laut genug, aber er hat noch nicht gemerkt, dass die 85jährige Frau Z. zwar sehr schwerhörig ist, aber überhaupt nicht schwer von Begriff. Er machen Sätze, als sie sein Türkin und nix Deutsch verstehen. Hoffentlich meldet Dr. L. das nächste Mal seinen Stellvertreter, wenn er für 4 Wochen in die Ferien abtaucht. Auch bei Chronischkranken kann es ja einmal akut werden. Da wäre es schon gut, wenn vorher festgehalten würde, wie weit man gehen will. Sonst gibt es immer wieder diese Verlegungen auf die IPS, die nachher niemand gewünscht hätte. Auch die Sterbenden nicht.

Und die skandalösen Geschichten, die ich dem Blick verkaufen könnte? Die behalte ich doch lieber für mich. In meinem Alter darf man es mit den Ärzten nicht verderben. Man weiss ja nie. 